\title{
Preparation and evaluation of (resorcinol - aldehyde) based polymeric dispersants for inkjet printing ink.
}

\author{
Ahmed S. Ahmed ${ }^{c}$, Nadia G. Kandile ${ }^{\text {a }}$, Nabel A. Negm ${ }^{\text {, }}$ \\ ${ }^{a}$ Chemistry Department, Faculty of Women, Ain-Shams University, Cairo, Egypt \\ ${ }^{b}$ Petrochemical Department, Egyptian petroleum research institute, Cairo, Egypt \\ ${ }^{c}$ R\&D Department, Degla chemicals, Cairo, Egypt
}

\begin{abstract}
In this study, modification of an amino polyether with resorcinol-aldehyde condensate was performed using four different aldehydes [formaldehyde, glutaraldehyde, butyraldehyde and 4(N,N-dimethylamino)benzaldehyde] to give dispersants $(1-5)$ to be used as dispersing agents for solvent based inkjet inks. The prepared dispersing agents were characterized using FT-IR and GPC. The optical properties and stability efficiency of the ink formulated with the prepared dispersing agents were investigated. The dispersants (1-5) were evaluated for their efficiency in comparison to commercial dispersing agents used in the market. Formulations of dispersants 4 and 5 showed excellent results in comparison to the commercial dispersing agents and have a good potential as effective dispersing agents for solvent based inkjet inks.
\end{abstract}

Keywords: Resorcinol, Aldehyde, Inkjet inks, dispersing agent, Pigment.

\section{Introduction:}

Inkjet printing was found to be an incredibly powerful tool for its economic and time efficient performance in short run jobs and was adapted to print other functional materials such as conductive inks, light emitting diodes (LED's) [1] and even three dimensional objects [2]. The inkjet printing process is very complicated, and their inks must meet tough requirements for storage stability, jetting performance, color management, wetting and adhesion to substrates [1, 3]. Inkjet inks are mainly classified according to the medium system used into (solvent based inks - water based inks - eco-solvent inks - UV inks - latex inks) [4], and according to the colorant used into (pigment based - dye based) [5].

Pigments are solid colored particles suspended in the ink medium. They need to be well dispersed and very small in size in order to give good color intensity and stable inks without precipitation to avoid clogging of the print-head [6], That's why pigment particle size should be less than 300 nanometers in order to ensure no clogging of the essential and very expensive printhead $[7,8]$.

*Corresponding author : a.sayed@deglachem.com 
This can be done by adding dispersing agents during ink manufacture to facilitate the breakdown of pigment particles and prevent them from recombining into particles of large sizes $[9,10]$.

Dispersing agents are specifically designed polymers which have a pigment affinic groups such as $\left(\mathrm{OH}-, \mathrm{COOH}-, \mathrm{NH}_{2^{-}}, \mathrm{NR}_{2^{-}}\right.$, aryl-, nitrile-, amide-, etc..) which adsorbs on pigment particle surface [11-13], and a solvent affinic chain (tail) such as (polyether - polyacrylate - polyester etc..) which extends in solution to provide steric stabilization against reagglomeration [14]. A combination of good anchor and good tail can be prepared through Mannich reaction. Mannich reaction essentially replaces the active hydrogen on a nucleophile such as resorcinol with an amino compound using aldehydes as a methylene bridge between the amine and the nucleophile as illustrated in Scheme 1 [15-19].

Scheme 1. Mannich reaction between formaldehyde, a primary amine and resorcinol under alkaline conditions

Resorcinol-aldehyde resins are well known and are being used in many applications such as adhesives, UV light stabilizers and printing inks [20, 21]. Many detailed studies on the chemistry and applications of resorcinol aldehyde resins have been done [22 - 34].

In the present work, we report herein the synthesis of new dispersing agents using polyether modified resorcinol-aldehyde condensate and the evaluation of their performance in inkjet ink formulations in comparison to commercial dispersing agents as a cheaper and easier to prepare alternative using mature industrial technology with at least the same quality as commercial dispersants.

\section{Experimental}

\subsection{Materials:}

Resorcinol (Oxford-India), Formaldehyde 37-41\% (Piochem-Egypt), Glutaraldehyde 25\% (Oxford-India), Butyraldehyde (Merck KGaA - Germany), 4-(N,N-dimethyamino)benzaldehyde (Oxford-India), Toluene (El-Mohandes - Egypt), Jeffamine M-2070 (Methoxy poly(oxyethylene/oxypropylene)-2-propylamine $\mathrm{Mw}$ 2000) (Huntsman-Belgium), Commercial inkjet organic pigment dispersant from (BASF-Germany) and carbon black dispersant from (Tianlong-Taiwan).

All reagents were used without further purification unless otherwise specified. 


\subsection{Instruments}

Bruker FT-IR analyzer; ALPHA-Platinum FT-IR Spectrometer with ATR Platinum-Diamond sampling modulefrom 400 to $4000 \mathrm{~cm}^{-1}$. Gel permeation chromatography (GPC) Agilent model 1515 pump system equipped with 1260 infinity refractive index detector and using THF as eluent. Operating with a flow rate of $1.00 \mathrm{ml} / \mathrm{min}$ at $35^{\circ} \mathrm{C}$. Column PL-gel $3 \mathrm{~lm}$ Mixed E 3007.5 $\mathrm{mm}$ covering a molecular weight range of $600-400,000 \mathrm{mg} / \mathrm{g}$ was used and was calibrated using polystyrene standards. Master size 3000 laser light scattering particle size analyzer: X-rite measurements (Relative color strength - $\Delta \mathrm{E}-$ Transparency) Printing ink strength, lightness and shade were measured using EXACT - PANTONE X-rite spectrophotometer, where; $\triangle \mathrm{E}$ represents the differences between samples and standard in these three parameters 1, a, b.Gloss The gloss of the printed film was measured on the printed polypropylene film using BIUGED BGD $514\left(60^{\circ}\right)$ gloss meter.

\subsection{Methods:}

Stability Test, Stability test of ink was performed according to (ASTM D 1849-95).

Adhesion Test, Adhesion was measured according to (ASTM D3359-02) and examined visually for the detached ink from the printed film.

Particle size testwas measured according to ASTM method D4464-00.

Dispersant solubility in common solvents, the test was performed for the prepared polymeric dispersants in which a 50:50 solution was prepared from the polymers and common solvents such as ethyl acetate, ethanol, water and toluene.

\subsubsection{Synthesis of dispersants (1-5).}

\section{General procedure 1 for preparation of dispersants (1-3)}

Resorcinol ( 1 mole) was mixed with ( 2 mole) of aldehyde and (1 mole) of Jeffamine M-2000, then $60 \mathrm{ml}$ of toluene were added. The reaction mixture was heated at $100-110^{\circ} \mathrm{C}$ for $7 \mathrm{~h}$ until completion of the reaction as monitored with FT-IR as no more aldehyde is detected.

\section{Dispersant 1}

The reaction was carried out using formaldehyde. A deep red viscous liquid was obtained, dried till over $99.0 \%$ nonvolatile matter (NVM). FT-IR shows the characteristic peaks at $3430-3460$ $\mathrm{cm}^{-1}$ for hydroxyl stretching, and $1610 \mathrm{~cm}^{-1}$ for $\mathrm{C}=\mathrm{C}$ aromatic stretching of resorcinol. Also increased bending peak at $1650 \mathrm{~cm}^{-1}$ for the methylene bridge of formaldehyde.

\section{Dispersant 2}

The reaction was carried out using butyraldehyde. A yellowish brown liquid of lower viscosity than dispersant 1 was obtained, which was dried till over $99.0 \%$ nonvolatile matter (NVM). FT- 
IR shows similar peaks to dispersant 1 except for the increased intensity of methylene and methyl bending peak at 1450 and $1380 \mathrm{~cm}^{-1}$ respectively due to the aliphatic carbon chain of butyraldehyde.

\section{Dispersant 3}

The reaction was carried out using N,N'-dimethylaminobenzaldehyde. A deep red viscous liquid was obtained, dried till over $99.0 \%$ nonvolatile matter (NVM). FT-IR shows a unique peak at $1300-1330 \mathrm{~cm}^{-1}$ due to the presence of tertiary amine stretching. Also an increase in aromatic double bond stretching at $1610 \mathrm{~cm}^{-1}$ due to the presence of 4-dimethylaminobenzaldehyde.

\section{General procedure 2 for preparation of dispersants $(4 \& 5)$}

Resorcinol was reacted with N,N-dimethylaminobenzaldehyde and glutaraldehyde for dispersants 4 and 5 respectively at $95-100^{\circ} \mathrm{C}$ for $1.5 \mathrm{~h}$, then $60 \mathrm{ml}$ toluene, Jeffamine $\mathrm{M}-2070$ and formaldehyde (37\%) were added under stirring then heated at $100-110^{\circ} \mathrm{C}$ for $6 \mathrm{~h}$, till completion of the reaction as monitored with FT-IR with no detectable aldehyde. Reaction products were then dried till over 99\% NVM.

\section{Dispersant 4}

The reaction was carried out as described in general procedure 2, using (1 mole) of N,Ndimethylaminobenzaldehyde and ( 2 moles) of resorcinol then added ( 3 mole) Jeffamine M-2070 and (4 mole) formaldehyde. A deep red viscous liquid was obtained and its FT-IR shows similar spectrum to dispersant 3 except for the lower intensity of tertiary amine stretching at 1300-1330 $\mathrm{cm}^{-1}$ and lower aromatic stretching at $1601-1650 \mathrm{~cm}^{-1}$ due to the lower content of 4(dimethylamino)benzaldehyde accompanied with increased methylene bending peak at $1450 \mathrm{~cm}^{-}$ ${ }^{1}$ due to the presence of formaldehyde.

\section{Dispersant 5:}

The reaction was carried out as described in general procedure 2. Reaction of (4 moles) resorcinol and ( 1 mole) glutaraldehyde first then $(7.5$ moles $)$ of formaldehyde, (4 moles) of Jeffamine M-2070 and $60 \mathrm{ml}$ toluene were added. A deep red viscous liquid was obtained and its FT-IR shows similar spectrum to dispersants 1 and 2 except for the increased aromatic stretching intensity at $1601-1650 \mathrm{~cm}^{-1}$ and hydroxyl stretching at $3450 \mathrm{~cm}^{-1}$ due to the higher concentration of resorcinol in dispersant 5.

\subsubsection{Inkjet ink formulation:}

All samples were ground using zircon beads at $100 \%$ of ink mass on a devil shaker. Table 1 shows the formulation used for the preparation of inkjet inks: 
Table 1: Inkjet ink formulation for testing dispersants (1-5)

\begin{tabular}{|l|l|}
\hline Chemicals & Weight percent \\
\hline Inkjet varnish & $92.5 \%$ \\
\hline Pigment & $5.0 \%$ \\
\hline Dispersant & $2.5 \%$ \\
\hline
\end{tabular}

\section{Results \& Discussion.}

The prepared dispersants (1-5) Scheme 2 have considerably higher viscosity than the starting polyether raw material, and dispersant 1 has the highest viscosity due to the lack of hindering side chain groups which means a more pronounced hydrogen bonding and interaction between polymer chains, while dispersant 2 has the lowest viscosity of all samples due the extensive presence of the softening and H-bond hindering aliphatic chain side groups of the butyraldehyde [35]. Prepared dispersants (1-5) are soluble in water, ethyl acetate, toluene and ethanol. 


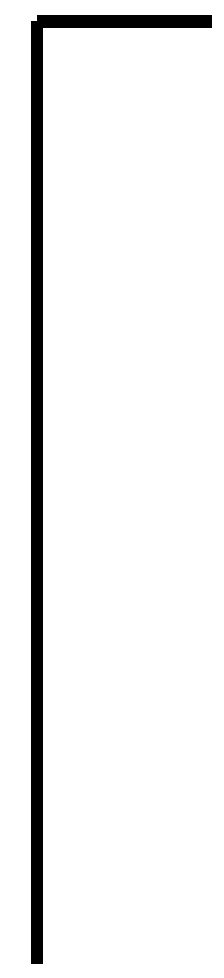

Scheme 2: Synthesis of targeted dispersants (1-5). 
Dispersants (1-5) had a deep red color except for dispersant 2 which has yellowish brown color. The deep red color is due to the side reaction of resorcinol with different aldehydes forming xanthene dye molecules $[32,36]$. Scheme3 shows the chemical formation of the red colored side product:

Scheme 3: Side reaction of resorcinol with aldehydes to form red xanthene dye[37]

Dispersant 2 however, didn't have this pronounced red color due to the slower rate of reaction of butyraldehyde as the reaction rate decreases with increasing the aliphatic chain due to steric hindrance[38].

\subsection{FT-IR Results:}

FT-IR spectra (Figure 1) of prepared dispersants (1-5) show the absence of $\mathrm{C}=\mathrm{O}$ stretching band of aldehyde at $1710-1740 \mathrm{~cm}^{-1}$ region, which indicates the reaction of the aldehyde [39,40]. However, resorcinol and N,N-dimethylaminobenzaldehyde showed their characteristic spectra at $1610 \mathrm{~cm}^{-1}$ for $\mathrm{C}=\mathrm{C}$ aromatic bending [41] vibration accompanied by $\mathrm{C}-\mathrm{H}$ aromatic stretching at $3030 \mathrm{~cm}^{-1}$. Characteristic bands of Jeffamine M-2070 at $2875 \mathrm{~cm}^{-1}$ and $2970 \mathrm{~cm}^{-1}$ [41] for the stretching vibrations of $\mathrm{CH}_{2}$ and $\mathrm{CH}_{3}$ groups, respectively, at $1450 \mathrm{~cm}^{-1}$ and $1370 \mathrm{~cm}^{-1}$ for the bending vibrations of $\mathrm{CH}_{2}$ and $\mathrm{CH}_{3}$ groups, respectively, at $1090-1093 \mathrm{~cm}^{-1}$ for the ether $\mathrm{C}-\mathrm{O}-\mathrm{C}$ stretching band of the polyether chain $[42,43]$. 


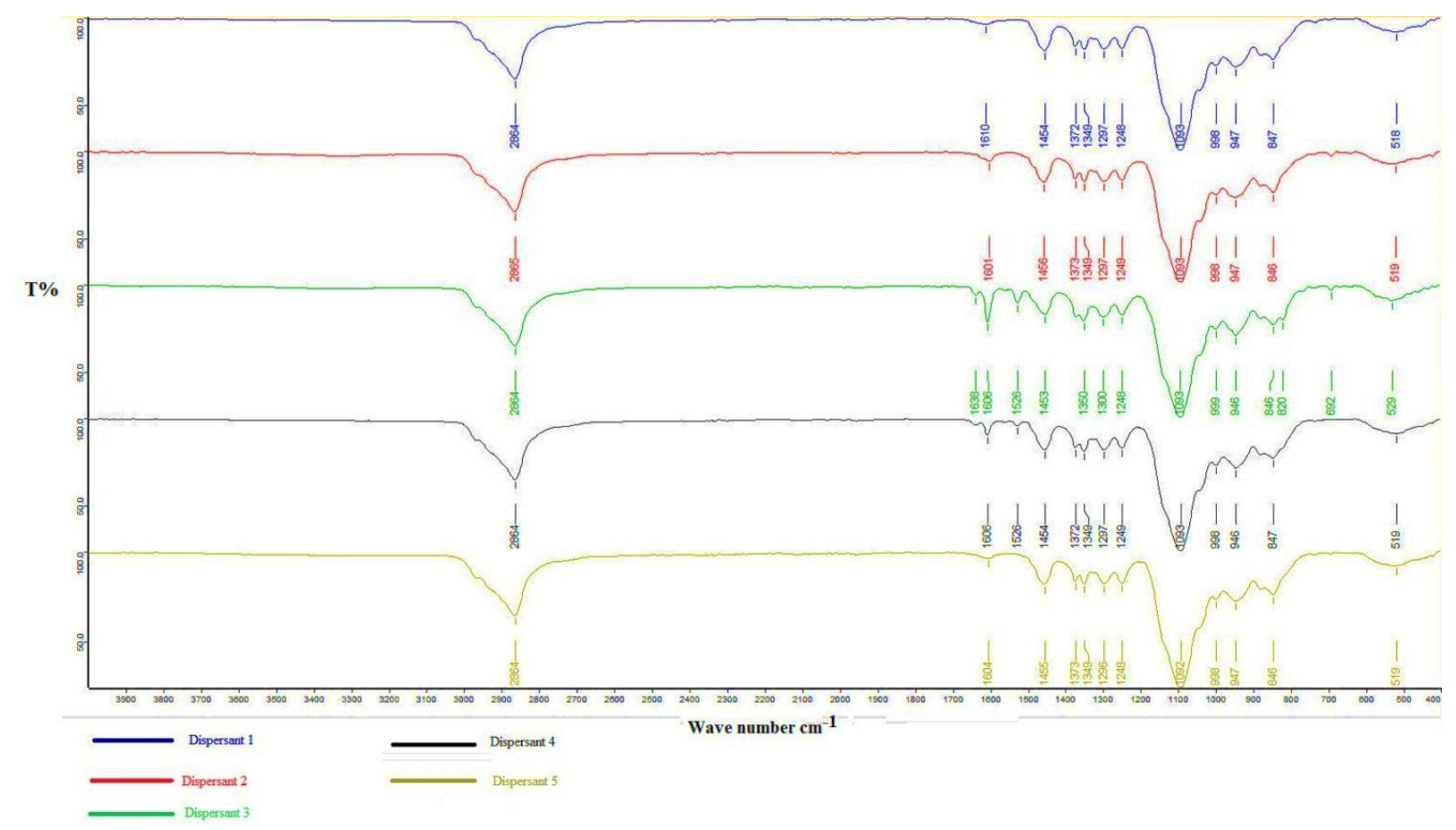

Figure 1: FT-IR spectra for Dispersants (1-5).

\subsection{GPC results:}

GPC results indicate the difference in molecular weight readings $\left(M_{n}, M_{w}\right.$ and polydispersity index "PDI") between the prepared dispersants and the polyether starting material Figure 2 and Table 2.

Table 2 GPC results of the five dispersants and the starting polyether raw material:

\begin{tabular}{|c|c|c|c|}
\hline Sample & $\mathbf{M}_{\mathbf{n}}$ & $\mathbf{M}_{\mathbf{w}}$ & PDI \\
\hline Dispersant 1 & 3,077 & 4,268 & 1.387 \\
\hline Dispersant 2 & 4,394 & 6,250 & 1.422 \\
\hline Dispersant 3 & 2,701 & 3,240 & 1.199 \\
\hline Dispersant 4 & 2,884 & 3,366 & 1.167 \\
\hline Dispersant 5 & 2,858 & 4,065 & 1.422 \\
\hline Jeffamine M-2070 & 2,158 & 2,505 & 1.160 \\
\hline
\end{tabular}




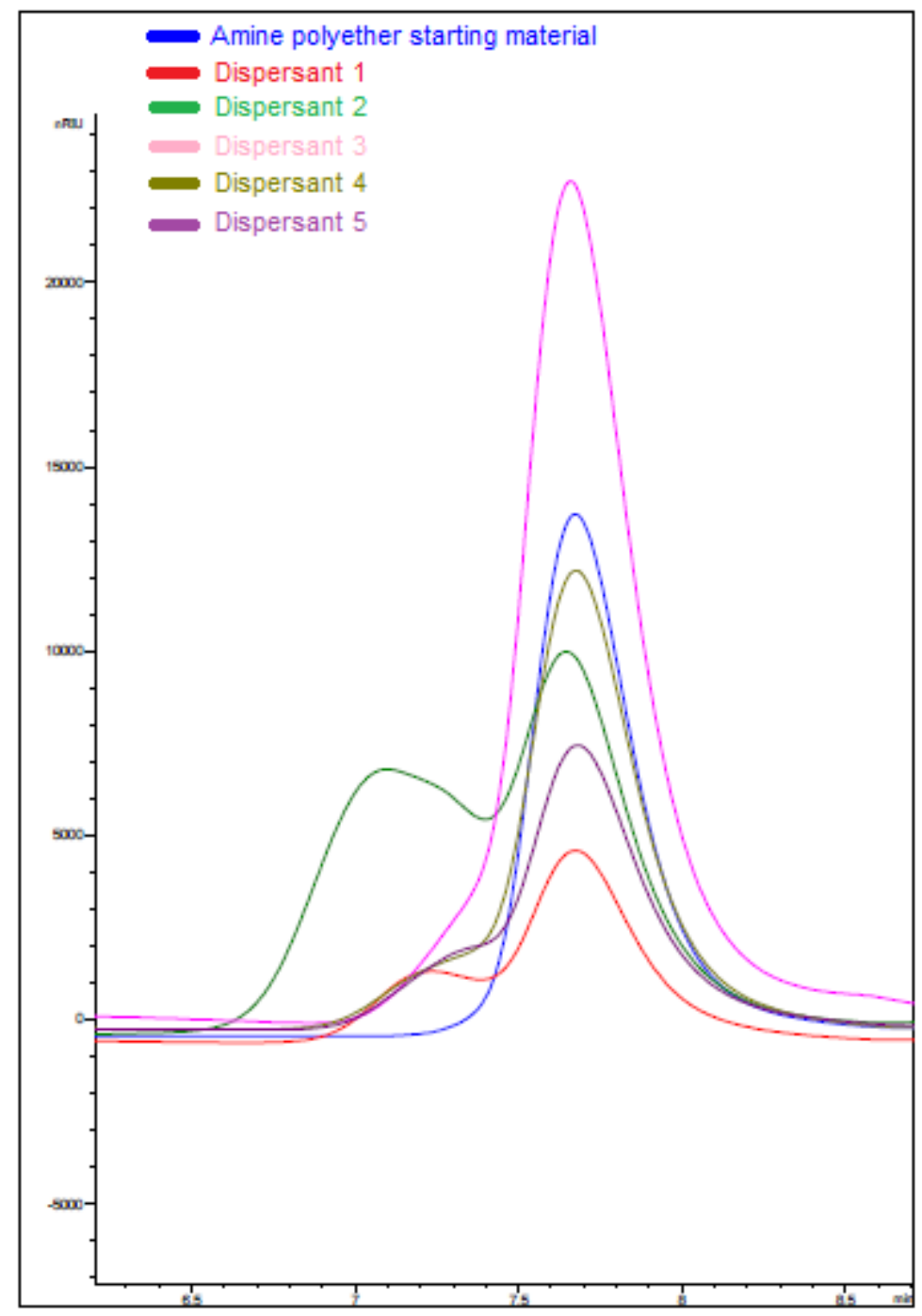

Figure 2: GPC chromatogram of polyether reactant and dispersants (1-5) final products.

The low reactivity of the high molecular weight mono-functional Jeffamine M-2070 allowed the reaction of resorcinol and aldehyde to proceed fairly to completion (form a large anchor core first) before it reacted with the resorcinol-aldehyde condensate using formaldehyde or methylol group as a bridge.

\subsection{Characterization of inks prepared using prepared dispersants (1-5).}

\subsubsection{Particle size distribution results for cyan 15: 3 and black 7 inks.}

\section{a. Cyan 15:3 inkjet inks:}

Particle size test results for cyan inkjet inks prepared with BASF commercial dispersant and the new prepared dispersants before and after stability (Table 3). 
Table 3, Particle size distribution of cyan 15:3 inkjet ink samples before and after accelerated stability test at $65^{\circ} \mathrm{C}$ for two weeks.

\begin{tabular}{|c|c|c|c|c|c|c|}
\hline \multirow{2}{*}{ Cyan (15:3) Sample } & \multicolumn{3}{|c|}{ Particle size in micrometers (+/- 0.02 $\boldsymbol{\mu m})$} \\
\cline { 2 - 7 } & \multicolumn{3}{|c|}{ Before } & \multicolumn{3}{c|}{ After (2 weeks at } \\
\cline { 2 - 7 } & \multicolumn{3}{|c|}{$\mathbf{6 5}^{\mathbf{}}$ ) } \\
\cline { 2 - 7 } & $\mathrm{D}_{10}$ & $\mathrm{D}_{50}$ & $\mathrm{D}_{90}$ & $\mathrm{D}_{10}$ & $\mathrm{D}_{50}$ & $\mathrm{D}_{90}$ \\
\hline Dispersant 1 & 0.056 & 0.120 & 0.249 & 0.057 & 0.122 & 0.257 \\
\hline Dispersant 2 & 0.058 & 0.123 & 0.257 & 0.060 & 0.130 & 0.267 \\
\hline Dispersant 3 & 0.059 & 0.125 & 0.259 & 0.059 & 0.126 & 0.266 \\
\hline Dispersant 4 & 0.057 & 0.121 & 0.250 & 0.058 & 0.124 & 0.258 \\
\hline Dispersant 5 & 0.057 & 0.120 & 0.247 & 0.057 & 0.122 & 0.254 \\
\hline BASF dispersant & $\mathbf{0 . 0 5 4}$ & $\mathbf{0 . 1 2 0}$ & $\mathbf{0 . 2 5 1}$ & $\mathbf{0 . 0 5 8}$ & $\mathbf{0 . 1 2 2}$ & $\mathbf{0 . 2 5 5}$ \\
\hline Blank & $\mathbf{0 . 0 7 7}$ & $\mathbf{0 . 1 8 0}$ & $\mathbf{0 . 7 1 6}$ & $\mathbf{0 . 1 3 2}$ & $\mathbf{0 . 4 2 1}$ & $\mathbf{1 . 8 9 6}$ \\
\hline
\end{tabular}

From the data in Table 3 all dispersants (1- 5) achieved excellent stability against precipitation and particle size growth with less than $5 \%$ growth in $\mathrm{D}_{90}$ particle size; Dispersants (2 and 3) achieved very good particle size results and good stability as well, yet were they had higher $\mathrm{D}_{90}$ than BASF dispersant and dispersants $(1,4,5)$. All prepared dispersants achieved excellent stability and particle size reduction while blank samples had mild precipitation.

\section{b. Black 7 (Carbon black)}

Particle size test results for black 7 inkjet inks prepared with Tian Long commercial dispersant and prepared dispersants (1-5) before and after stability are presented in Table 4:

Table 4 Particle size distribution of black 7 inkjet ink samples before and after accelerated stability test at $65^{\circ} \mathrm{C}$ for two weeks

\begin{tabular}{|c|c|c|c|c|c|c|}
\hline \multirow{2}{*}{ Carbon Black Sample } & \multicolumn{3}{|c|}{ Particle size micrometers (+/- 0.02 $\boldsymbol{\mu m}$ ) } \\
\cline { 2 - 7 } & \multicolumn{4}{|c|}{ Before } & \multicolumn{3}{c|}{ After (2 weeks at } \\
& \multicolumn{3}{|c}{$\mathbf{6 5}^{\mathbf{0}} \mathbf{}$} \\
\cline { 2 - 7 } & $D_{10}$ & $D_{50}$ & $D_{90}$ & $D_{10}$ & $D_{50}$ & $D_{90}$ \\
\hline Dispersant 1 & 0.020 & 0.056 & 0.143 & 0.020 & 0.061 & 0.145 \\
\hline Dispersant 2 & 0.020 & 0.054 & 0.140 & 0.020 & 0.060 & 0.149 \\
\hline Dispersant 3 & 0.020 & 0.055 & 0.145 & 0.020 & 0.060 & 0.147 \\
\hline Dispersant 4 & 0.020 & 0.053 & 0.145 & 0.020 & 0.056 & 0.148 \\
\hline Dispersant 5 & 0.020 & 0.053 & 0.144 & 0.020 & 0.059 & 0.143 \\
\hline Tianlong dispersant & $\mathbf{0 . 0 2 0}$ & $\mathbf{0 . 0 5 4}$ & $\mathbf{0 . 1 4 5}$ & $\mathbf{0 . 0 2 1}$ & $\mathbf{0 . 0 5 8}$ & $\mathbf{0 . 1 4 8}$ \\
\hline Blank & $\mathbf{0 . 0 1 9}$ & $\mathbf{0 . 0 5 0}$ & $\mathbf{0 . 1 9 8}$ & $\mathbf{0 . 0 7 6}$ & $\mathbf{0 . 1 5 8}$ & $\mathbf{0 . 3 6 3}$ \\
\hline
\end{tabular}


From data in Table 4, prepared dispersants (1-5) achieved excellent stability against precipitation and particle size growth with less than $2.5 \%$ growth in $\mathrm{D}_{90}$ particle size after stability, except for dispersant 2 which had $6.4 \%$ growth after 2 weeks at $65^{\circ} \mathrm{C}$. Blank sample on the other hand suffered from mild precipitation

\subsubsection{X-Rite, Adhesion \& Gloss meter results:}

All formulations prepared using the new dispersants provided films with excellent adhesion on polyvinyl chloride (PVC) substrate. The results for specular gloss and relative color strength in comparison to the commercial dispersing agent are listed in Table 5:

Table 5 Specular gloss and relative color strength of inkjet ink films prepared with dispersants (1-5) against commercial standard.

\begin{tabular}{|c|c|c|c|c|c|}
\hline \multirow[t]{2}{*}{ Color } & \multirow{2}{*}{ Sample } & \multicolumn{2}{|c|}{ Gloss $(\mathbf{G U})^{\circ}$} & \multicolumn{2}{|c|}{$\begin{array}{l}\text { Relative color } \\
\text { strength } \Delta \mathbf{S \%}\end{array}$} \\
\hline & & Before & After & Before & After \\
\hline \multirow{7}{*}{ Cyan $(15: 3)$} & Dispersant 1 & 58.1 & 52.1 & 93.1 & 99.3 \\
\hline & Dispersant 2 & 54.2 & 52.7 & 97.2 & 94.8 \\
\hline & Dispersant 3 & 61.3 & 57.9 & 100.1 & 95.4 \\
\hline & Dispersant 4 & 59.8 & 59 & 98.6 & 100.4 \\
\hline & Dispersant 5 & 62.7 & 60.9 & 101.2 & 100.3 \\
\hline & BASF Dispersant & 60.5 & 57.8 & 100 & 100 \\
\hline & Blank & 47.2 & 32.4 & 77.3 & 69.8 \\
\hline \multirow{7}{*}{ Black 7} & Dispersant 1 & 94.1 & 89.7 & 114.1 & 116.5 \\
\hline & Dispersant 2 & 88.2 & 83.3 & 93 & 89.9 \\
\hline & Dispersant 3 & 87.0 & 80.2 & 96.1 & 81.5 \\
\hline & Dispersant 4 & 92.6 & 91.1 & 100.3 & 113 \\
\hline & Dispersant 5 & 94.8 & 92.6 & 108.2 & 103.3 \\
\hline & Tian Long Dispersant & 93.6 & 91.9 & 100 & 100 \\
\hline & Blank & 57.0 & 45.3 & 70.5 & 62.1 \\
\hline
\end{tabular}

From the data in Table 5, dispersants 4 and 5 achieved the best color strength, specular gloss among the prepared dispersants and were comparable in quality to the commercial dispersant in cyan 15:3 inks and proved successful in this type of inkjet inks. Dispersants 1, 2 and 3 had good color strength and specular gloss, yet they were lower in quality than the commercial dispersant.

Black 7 results from data in Table 5 show that dispersant 1, 4 and 5 had the best color strength (black jettness) and specular gloss among the prepared dispersants of present work, they were 
comparable in quality to the commercial dispersant and proved effective dispersing agents for carbon black inkjet inks.

The high reaction rate of resorcinol with aldehydes enables good yields even with some of the less reactive aldehydes [20]; the two hydroxyl groups on the resorcinol molecule along with the electron rich benzene ring give it the possibility of bonding with a wide range of pigments of different chemical structures.

The use of functional aldehydes can significantly increase the anchoring effect towards the pigment surface, for example, 4-(N,N-dimethylamino)benzaldehyde had the direct advantage of the presence of tertiary amine to give effective dispersant and is also the least sensitive to surface moisture [12], While glutaraldehyde had the indirect advantage of increasing the anchor sites through its bi-functional aldehyde. Butyraldehyde on the other hand had the disadvantage of lower wettability of the saturated aliphatic short chain of butyraldehyde to the compact aromatic surface of most organic pigments and carbon black which is mainly due to the lower Pi $(\pi)$ electrons interaction with surface Pi electrons cloud on the compact aromatic structure.

The lowest dispersing performance was obtained by dispersant 3 which has the highest density of aromatic moiety closely stacked together along its anchor chain. This in turn increases affinity of the fully aromatic dispersant anchor molecules to each other (head to head) in competition to their affinity to the pigment surface. Best results however, were obtained by dispersants 4 and 5 which had the most convenient polarity with regards to the pigment surface.

The low reactivity of the high molecular weight mono-functional amine polyether allowed the reaction of resorcinol and aldehyde to proceed fairly to completion (form a larger and more efficient anchor core first) before it reacted with the resorcinol-aldehyde condensate through formaldehyde or methylol group as bridge. The manipulation of such resins to comply with the requirements of inkjet dispersants (Good anchor group and good tail) can provide an effective dispersing agent with very good mechanical (especially adhesion to substrate) and optical properties, the diversity of possible aldehydes and good reaction rate of resorcinol provide good opportunity to control the polarity and functionality of the anchor group to be compatible with many pigments of different chemical families used in the inkjet printing industry.

\section{Conclusion:}

In this study, a series of new dispersing agents were prepared by modification of polyether amine with different resorcinol-aldehyde condensates to produce dispersing agents (1-5). Inkjet ink formulations were prepared and evaluated in comparison to a commercial dispersing agent in terms of particle size, optical and mechanical properties as well as accelerated stability to provide a cheaper and easier to prepare alternative using mature industrial technology alternative to commercial dispersants. Evaluation results showed that dispersants 4 and 5 had the best performance among the other prepared dispersants in terms of particle size and optical properties and comparable to the commercial dispersants tested. Dispersants 4 and 5 showed a very good 
potential as inkjet dispersants, while dispersant 1 exhibited a very good performance in terms of particle size but was lower in optical qualities compared to the commercial dispersants used.

\section{References:}

A. Bobrowski and B. Grabowska, FTIR method in studies of the resol-type phenol resin structure in the air atmosphere over certain time intervals, Metallurgy and Foundry Engineering , 41(3), (2015), 107-113.

A. M. ElKhatat and S. A. Al-Muhtaseb, Advances in Tailoring Resorcinol -Formaldehyde Organic and Carbon Gels, Adv. Mater. 23 (2011), 2887-2903.

B. A. Makwana, K. Bhatt, D. Vyas, H. S. Gupte, and V. K. Jain, Synthesis, Characterisation, Binding Behavior and Antimicrobial Activity of Azocalix[4]Resorcine dye derived from 8aminoquinoline, Sch. Acad. J. Pharm., 3(6): 2014, 463-470.

B. El-Gammal, G.M. Ibrahim, and I.M. El-Naggar, Preparation of some resorcinol formaldehyde resins for the separation of 134CS from acidic waste streams, Desalination and Water Treatment, 52 (2014) 25-27.

C.T. Kosolia, E.M. Varka and E.G. Tsatsaroni, Effect of Surfactants as Dispresing Agents on the Properties of.Microemulsified Ink-Jet Inks for Polyester Fibers, Journal of Surfactants \& Detergents, (2011) 14:3-7.

D. A. Dillard, Adhesion Science and Engineering: Surfaces, Chemistry and Applications, first ed., Elsevier science, (2002) 918-919.

E. P. Sampler, Some aspects of the chemistry of cyclic aminol ethers, PhD. Dissertation, Loughborough University, July-2001.

F. L. Duivenvoorde, Pigment dispersing in powder coatings: synthesis and use of block copolymer dispersing agents, Eindhoven: Technische Universiteit Eindhoven (2000).

F.O.H. Pirrung; P.H. Quednau and C. Auschra, Wetting and Dispersion Agents. Chimia, 56, (2002) 170-176.

G. L.Güngör,A. Kara,M.Blosi,D.Gardini,G.Guarini,C.Zanelli andM.Dondi, Micronizing ceramic pigments for inkjet printing: Part I. Grindability and particle size distribution, Ceramics International journal, 41 (5), Part A, (2015) 6498-6506.

H. Warson and C.A. Finch, Applications of Synthetic Resin Latices Vol.1, first Ed., John Wiley \& Sons, Ltd, Chichester, (2001) 618. 
http://chemistry.tutorvista.com/organic-chemistry/mannich-reaction.html.

http://www.chem.ucla.edu/ bacher/General/30BL/IR/ir.html.

http://www.freedompaper.com/wide-format-ink-types.

Infrared Spectroscopy and NMR Table. Rose-Hulman institute of technology.https://www.rose-hulman.edu/ brandt/Chem252/IR_and_NMR_tables.pdf

Infrared Spectroscopy Table, The UCLA Chemistry \& Biochemistry Department.

J. A. Heredia-Guerrero, J. J. Benitez, E. Dominguez, I. S. Bayer, R. Cingolani, A. Athanassiou and A. Heredia, Infrared and Raman spectroscopic features of plant cuticles: a review, Frontiers in Plant Science, 5 (June 25th- 2014): 305.

J. Coates, Interpretation of infrared spectra, a practical approach, Encyclopedia of Analytical Chemistry, John Wiley \& Sons, Ltd, (2006).

http://www3.uma.pt/jrodrigues/disciplinas/QINO-II/Teorica/IR.pdf

J. Mendel, D. Bugner. and A.D. Bermel, Particle generation and ink particle size effects in pigmented inkjet inks - Part II, Journal of Nanoparticle Research, 1(1999) 421-424.

J. Ward, Ink Jet Dispersions: Challenges \& Opportunities, IMI Ink Jet Conference, February (2015)5-6.

J.T. Kunjappu, Polymers in Ink Chemistry, Ink world magazine, (2009).

K. Tabatabaeian andA.Khorshidi, A. Dadashi, M.Khoshnood, Efficient Ru III-catalyzed synthesis of 9-aryl-9H-xanthene-3,6-diols as precursors to fluorones, Chinese Chemical Letters, 23(2), (2012), 165-168.

M. Colonna, C. Gioia, M. Vanninia, M. Fiorinia, A. Cellia, A. Minesso, R. Cava;ieri and E. Kubillus, One-pot melt synthesis of resorcinol based polyarylates for UV-stable coatings, Progress in Organic Coatings 77 (2014), 1701-1708.

M. Patel, A study of the Mannich reaction with certain phenols, of the causes of formation of colored products and the prevention of their occurrence, Brunel university dissertation, May 1979.

M.M. Marie, Y.H. El-Hamaky, D. Maamoun, D.F. Ibrahim, and S.M. Abbas, Pigment Ink Formulation for Inkjet Printing of Different Textile Materials, International Journal of Innovation and Applied Studies, 4 (2013) 239-247. 
Mannich reaction mechanism.

N. K. Beyeh, A. Valkanenab, and K. Rissanen,Deprotonation of resorcinarenes by mono- and diamine bases: complexation and intermolecular interactions in the solid state Cryst Eng Comm, 16 (2014), 3758.

N. St. Luce, Synthesis, characterization and study of novel reagents for the detection of saccharides and amino acids, $\mathrm{PhD}$ dissertation, Louisiana State University and Agricultural and Mechanical College, May-2004, Pg 1-7.

O.A. Hakeima, A.A. Arafaa, M.K. Zahranb and L.A.W. Abdou, UV-curable Encapsulation of surface-Modified organic pigments for inkjet printing of textiles, 447 (2014) 172-182.

P. Beck, Synthesis and analysis of three-dimensional molecular architectures, Louisiana State University, Agricultural and Mechanical College, Dissertation December 2001.

P. Chauhan, Synthesis and Characterization of Phenolic Resins, TECHNOFAME :A Journal of Multidisciplinary Advance Research, 3 (1), (2014) 117-121.

P. Santhana Gopala Krishnan, N. Venkatesan and K. Adhinarayanan, Effect of phenolic resin structure on the bonding properties of nitrile rubber-based adhesives, Journal of Adhesion Science and Technology 18(13) (2004):1483-1495.

P. Timmerman, W. Verboom and D.N. Reinhoudt, Tetrahedron, 52 (8), (1996) 2663-2704.

R. B. Durairaj, Resorcinol: Chemistry, Technology and Applications, first ed. Indspec Chemical Corporation, New York, 2005, Pg 181.

R. W. Hemingway and J.Karchesy, Chemistry and Significance of Condensed Tannins, first ed. Washington, (1988)232.

S. J. Taylor, M. D. Haw, J. Sefcik and A. J. Fletcher, Gelation mechanism of resorcinolformaldehyde gels investigated by dynamic light scattering, Langmuir, 30 (34) (2014) 1023110240.

S. Magdassi, The chemistry of inkjet inks, first ed.World scientific, Singapore (2010)Pg vii.

S. Mulik, C. S. leventis and N. Leventis, Acid-catalyzed Time-efficient Synthesis of Resorcinol-Formaldehyde Aerogels and Crosslinking with Isocyanates, Polymer Preprints American Chemical Society (ACS), 47(2), (2006) 364-365.

T. Lamminmäki, J.P. Kettle and P.A.Gane, Colloids and Surfaces A: Physicochem. Eng. Aspects, 380 (2011) 79-88.

U. Currle, R. Moebius and K. Krueger, 4th IMAPS/ACerS International Conference and Exhibition on Ceramic Interconnect and Ceramic Microsystems Technologies 2008 (CICMT 2008). 
V. Haak and J.W. Henk, Design of pigment dispersants: Methodology for selection of anchoring groups, Journal of Coatings Technology, 69 (1997) 137-142.

V. Shukla, M. Bajpai andF. Habib, "Mannich base: a cost effective, low temperature curing agent for epoxides", Pigment \& Resin Technology, 36 (3), (2007), 169 - 171.

W. Senapak, R. Saeeng and U. Sirion, One-pot three-component Mannich-type reactions catalyzed by [bsmim] [HSO4]/Cu(OTf)2, Proceedings of the Burapha University International Conference 28-29 July (2016), Bangsaen, Chonburi, Thailand.

Wide Format Ink Types for Inkjet Printers.

X. Zhou and A. Pizzi, Tannin-resorcinol-aldehyde cold-set wood adhesives with only formaldehyde as hardener, Eur. J. Wood Prod, 71 (2013)537-538.

Y. K. Voronina, A.R. Burilov andM.A. Pudovik, Modification of bicyclic phosphonates based on resorcinol and its derivatives via Mannich reaction, Journal of Phosphorus, Sulfur, and Silicon and the Related Elements, 191(11) (2016) 1560-1561. 


\section{الملخص باللفة العربية}

تحضير وتقييم مشتتات بوليمرية مبنية علي (ألد هيد - ريزولسينول) لأحبار الطباعة بالنفث.

نادية غريب قنديل1 ،نبيل عبد المنعم نجم²، أحمد سيد أحمد3

1 قسم الكيمياء، كلية|البنات، جامعه عين شمس، القاهرة، مصر.

2 قسم البتروكيماويات، معهد بحوث البترول، القاهرة، مصر.

3 قسم البحوث و التطوير، شركة دجلة للكيماويات، القاهرة، مصر.

في هذه الدر اسة تم تعديل أمين متعدد الايثر بو اسطة ناتج تكتيف الريزولسينول - ألدهيد، وذلك باستخدام أربعة ألدهيدات (فور مالدهيد - جلوتار الدهيد - بيوتير الدهيد - ثنائي ميثيل أمين بنز ألدهيد) وذلك لإنتاج المشتتات ( 1 - 5) و إستخدامهم كعو امل مشتتة لأحبار النفت المبنية علي المذيبات العضوية. تم توصيف العو امل المشتتة التي تم تحضير ها بإستخدام FT-IR و GPC. كما تم التحقق من الخواص البصرية وكفاءة

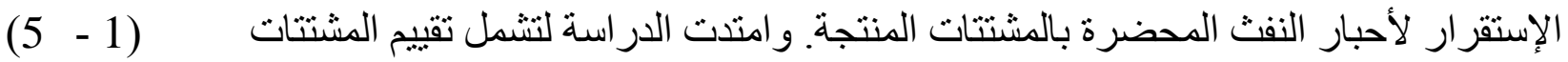
المحضرة مقارنة بمشتتات تجارية مستخدمة في أحبار النفث في السوق، وتبين من نتائج الدراسة أن تركيبات

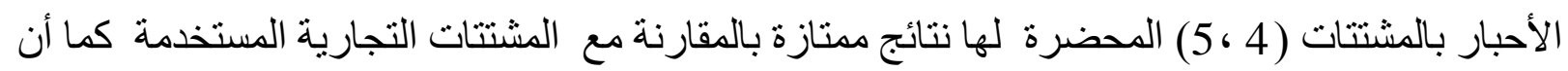
لها إمكانية جيدة لتكون عو امل مشتتة فعالة لأحبار النفث في المذيبات العضوية. 